\title{
Surface and Depth: Metalanguage and Professional Development in Canadian Writing Studies
}

Katja Thieme

University of British Columbia

\section{Introduction}

This paper began as part of a panel at the conference of the Canadian Association for the Study of Discourse and Writing (CASDW) in 2017 at Ryerson University. In the proposal for this panel, Heidi Darroch quoted Margaret Marshall's critical discussion of the informal structure of teaching circles. According to Marshall, these teaching circles had important functions for disciplinary mentoring and training of out-of-field instructors of writing courses. She notes that among the participants of these teaching circles not all "want to know more about composition and rhetoric scholarship"; some may instead wish to "learn something concrete that they think will enhance their teaching-like using technology more effectively-but they may have no interest in learning the underlying research or theoretical perspectives that might inform those practices" (Marshall, 2008, p. 428). Heidi's prompt for that panel helped me think more systematically about the tension between the surface and depth in mentoring writing instructors, the important roles that metalanguage plays in mediating that tension, and the indignities of contract employment that in many ways prevent writing instruction in Canada from becoming the deep and thoroughly researched practice that it could be.

\section{Surface and Depth in Talking about Teaching Writing}

I am intrigued by the metaphoric contrast between practical surface and underlying theoretical depth that is invoked by Marshall's point about some of the participants in her initiative. We can map this metaphoric contrast onto the distinction between short-term work that requires flexible course planning and longterm work that invites dedication to the research and pedagogy of a discipline. Such a contrast describes the difference between travelling through a one-term sessional course assignment and embarking on a 
Volume 29, 2019

http://journals.sfu.ca/cjsdw

dissertation-length journey. Such a contrast also expresses the assumption that it is possible to move somewhat sure-footedly through a term-length course-to walk along this surface of practical day-to-day teaching choices - if given some basic guidelines informed by the deeper theories below. This assumption is systemic; it is built into the machinery of contingent teaching. As a result, it is an idea that is held, by necessity, by a considerable number of those who are in a position to assign new instructors to writing courses as well as those who work as writing instructors on a contingent basis. Those in a position to assign new instructors must enact this assumption-the assumption that it is possible to teach writing studies by walking the surface-particularly if almost all apply to such teaching without them having been trained in writing studies pedagogies or having had the opportunity to engage in writing studies research (Martin, 2003; Samuels, 2017; Wardle, 2013).

In some ways such a dance on the surface is possible-many contingent instructors admirably prove so each academic year. Some instructors can successfully run writing courses this way, one year, another year, even many years in a row; they can capably guide students to produce good research papers with such an approach; they can effectively teach a course that has been developed in this way by adapting it for multiple different institutions. For others, the dissonance between what they know about writing from their own experience and what the systematic knowledge of the discipline suggests is too great to make them effective. In the long term, however, for the continued well-being of writing research and instruction in Canada, university writing teachers need access, time, and incentives to contribute to theoretical discussion and ongoing empirical research in writing and discourse studies (Landry \& Thieme, under review). Without knowledge of the structure that connects and sustains writing studies as a research field - a field which exists beyond the classroom-and without links from our teaching to the ongoing inquiries happening in this and its related fields, the success of pedagogical work across different instructors and sections will remain unstable, uncertain, and hit-and-miss.

As a result, I argue that we need to challenge this surface-depth metaphor and advocate at all administrative levels for actively bringing elements of the theoretical structures and concepts into the work that instructors do with students in writing studies classes. The underlying tenets of our disciplineour shared "threshold concepts" (Adler-Kassner \& Wardle, 2015), our rich technical language (Hyland, 2006), our various methods of inquiry (Nickoson, Sheridan, \& Kirsch, 2012) — should not only inform our work in the writing courses we teach, these underlying tenets should also be a visible part of those courses. By making them visible, we allow students to catch glimpses of the world of research and study that shapes what we do and outlines paths of inquiry which reach beyond the introductory courses we teach. It is particularly essential to keep providing such glimpses-to students, to other instructors, to 
Volume 29, 2019

http://journals.sfu.ca/cjsdw

administrators - in a field that, across the country, is at perpetual of risk of being de-railed and dedisciplined (Alexander, 2005; Giltrow, 2016; Phelps, 2014). By way of illustration, the following section will describe some of the ways in which my unit at the University of British Columbia in Vancouver (UBC-V) has used metalanguage in order to habituate and maintain connection to writing studies research among our instructors and our students. I will end on a critical consideration of how employment conditions can get in the way of maintaining and nourishing these connections between writing studies research and teaching.

\section{The Role of Metalanguage}

A key tenet of different pedagogical approaches in applied language studies is the necessity of using metalanguage in one's teaching (Downs \& Wardle, 2007; Duff, Ferreira, \& Zappa-Hollman, 2015; Hyland, 2003; Thieme, 2016). The concept of metalanguage has a long history in the study of logic and has been embraced by applied language scholars as a term that describes both the language knowledge that is tacitly held by language teachers as well as the language that is explicitly used in the teaching of language (Berry, 2005). In contrast to the idea of pure metalanguage in semantics and logic, metalanguage in applied language studies is "reflexive" and full of "the imprecisions of natural language" (Berry, 2005, p. 7). In applied linguistics, the definition of metalanguage is often shortened to "language about language" or "language used to describe language," but such broad definitional phrases can be misleading as, for my purposes, there is a need to distinguish between learners' and researchers' language about language. Whereas learners' language about language will more firmly fall into the field of folk linguistics, writing instructors' language about language should not. It should fall into the realm of writing studies and applied language research and thus provide a traceable link between the surface of classroom activity and the depth of disciplinary theory, traceable by both students who might wish to know more about the field, as well as traceable by other instructors who might wish to study, understand, and adapt elements of each other's teaching.

In other words, I advocate that writing instructors move away from speaking about elements of writing in lay or metaphoric terms. Instead, instructors need to move towards integrating the technical language developed by the discipline, the metalanguage used in writing studies research. It is through metalanguage that the visible surface in teaching and the underlying depth of research are linked-metalanguage enables analysis of others' writing, inquiry into different genres, and development of self-regulated writing strategies. The productive and functional metalanguage I have in mind is not the language of correction, textual deficits, or negative evaluative reaction to students' texts. Mary Schleppegrell reminds us that linguistic terminology is not in itself "supportive of other learning goals" (Schleppegrell, 2013, p. 156), and 
Volume 29, 2019

http://journals.sfu.ca/cjsdw

therefore needs to be selected and integrated so as to work in the service of those learning goals. In other words, to be productive, metalanguage in writing studies teaching should empower students to participate in the tasks of genre analysis and production so as to become effective agents in the discourse communities for which writing courses prepare them. Common across different approaches to teaching metalanguage is an emphasis on language use as socially situated-indeed, the social situatedness of all writing is a central concept found in all current branches of writing, discourse, and applied language studies (Artemeva, 2008). Thus, metalanguage needs to support "authentic engagement in meaning-making" in such a way that the technical language provided stimulates "the noticing, consciousness-raising, and focused attention" that produces written genres which work in their social contexts (Schleppegrell, 2013, p. 156).

\section{Putting Metalanguage to the Test}

The metalanguage that has been highly productive in writing studies classes in Arts Studies in Research and Writing (ASRW) at UBC-V has come from, for instance, conceptualizations of academic writing as Janet Giltrow has elaborated them (Giltrow, Gooding, Sawatsky, \& Burgoyne, 2014), genre move analysis in the way John Swales has developed (Swales, 2004), pragmatic language analyses as Ken Hyland has carried out (Hyland, 2004), or systemic functional linguistic perspectives on academic English learning as MAK Halliday has instigated (Halliday \& Martin, 1994). Using metalanguage in a writing studies class means students are asked to understand and adopt some of the language of writing research as it currently exists. Such a request entails that students can demonstrate their understanding of such language in the process of assessment, for instance by accurately identifying relevant language elements in others' research writing as well as by appropriately employing those elements in the production of their own texts. In one of the most challenging elements of ASRW writing studies courses, students are tested on their knowledge of metalanguage in a stylistic or discourse analysis assignment. Adopting some of this metalanguage, not only being able to use it correctly, but also engaging it in order to advance arguments about academic writing, are highly demanding tasks. It is challenging work for students to learn this type of language analysis and to discipline themselves to look at research genres in this way. It is also serious work for writing instructors to learn to teach in this way, to excel at it, and to help students see and feel the purposes of this approach.

In ASRW at UBC-V, there is not a required set of metalanguage terms that students are expected to learn or that instructors are expected to teach. There is some freedom for instructors to focus on terms that link with their training or that correspond to their approaches to teaching. Whereas, in our unit, I am one of the very small number of faculty on a tenure track, the vast majority of our instructors are contract instructors 
who, in most cases, have not been trained in writing studies. UBC-V is not unique in relying on such a high proportion of contract employment in staffing its writing studies courses (Landry, 2016; Smith, 2006). ASRW contract instructors often maintain research profiles that lie outside the discipline of writing studies; all of them have PhDs but these are, for instance, in medieval literature, $18^{\text {th }}$ century English literature, American literature, Canadian literature, children's literature, South African literature, music, cognitive studies, philosophy, film studies, geography, or literacy education. Our unit addresses this diversity of training by setting up intensive mentoring for new instructors, offering pedagogy workshops, inviting guest speakers, encouraging sharing of materials, and visiting each others' classes.

Out-of-field instructors might be inclined to question the insistence on teaching writing through metalanguage, and perhaps also the imposition on them when being asked to think about writing in those particular technical terms. However, in the short history of ASRW, instructors who have joined with training from other fields have also been excited and grateful for the possibilities afforded by the use of metalanguage and of research-based approaches to teaching writing. Disciplinary metalanguage is highly important to a writing course if we want these courses to have a greater degree of success-if we want there to be ripple effects and paths for growth beyond the end of a term. Teaching metalanguage fulfills multiple functions in a writing studies course (figure 1):

1. Metalanguage enables analysis of course texts-in ASRW's case, the analysis of the multi-disciplinary research articles-and through this ongoing analysis the discovery of disciplinary patterns and disciplinary differences in language use and genre structure.

2. Metalanguage instructs students to think of genre moves and language features in an abstracted way that in turn allows them to recognize why and how genre moves are linked to particular types of expression. Ideally, being aware of these patterns and giving names to their parts will help selfregulated, strategic thinking for approaching and successfully mastering new types of genres.

3. Metalanguage guides students' feedback when they are asked to conduct peer review on each others' assignments. Establishing expectations around genre moves as well as the technical language used to analyze the elements of a text enables even the most novice writer to recognize and helpfully comment upon another novice writer's writing-in-progress.

4. Metalanguage links what happens in this one writing studies course to the larger world of research in the fields of applied language studies, rhetoric, and discourse analysis, and thereby animates broader discussions about research and writing, offering wider purpose to the still-alien-to-them writing students are asked to do in a research writing course. 
Volume 29, 2019

http://journals.sfu.ca/cjsdw

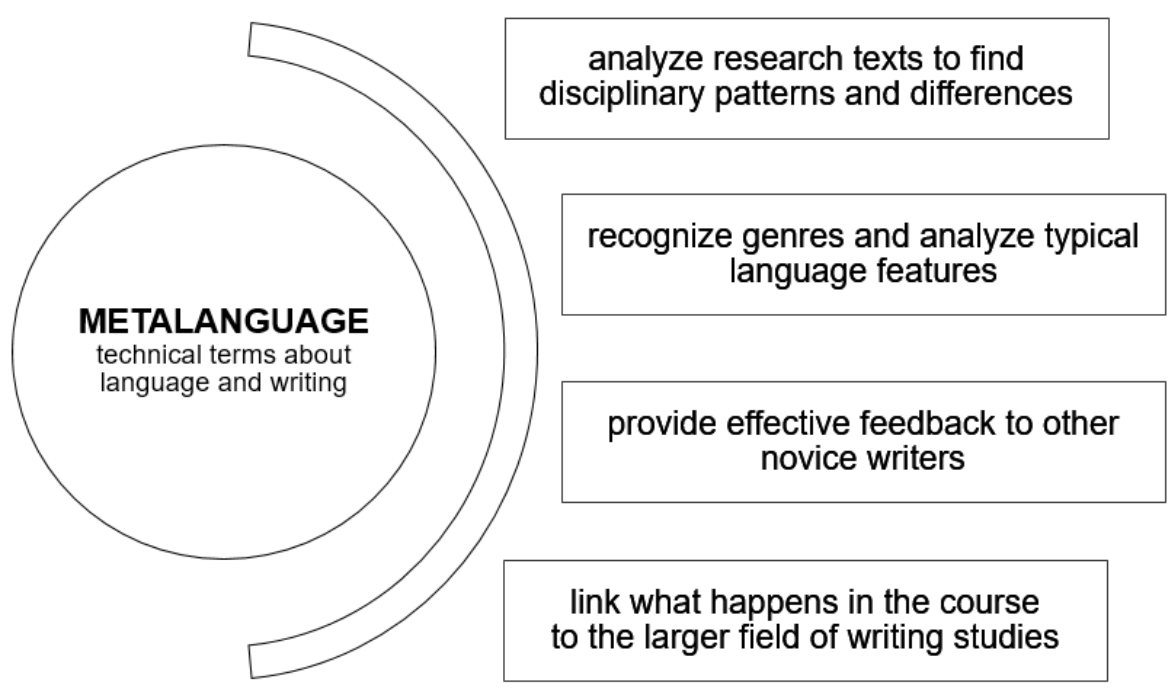

Figure 1: Functions of metalanguage in a writing studies course.

\section{Power and Precarity}

The above are the key elements that from my writing research perspective I want metalanguage to do. I have worked in ASRW first as a contract lecturer, later as a tenure-track instructor, and also as a chair. I have contributed to years of effort to put our writing instruction on a strong, research-based footing that teaches applied language approaches to disciplinary discourse and research genres. These efforts are intended to collegially invite instructors into the field of writing studies. ASRW prides itself on being a very supportive unit, and we have consistently built professional development into our term schedule. We have been quite successful and several of our instructors have managed to relay the writing studies work they were able to do in our unit into more permanent positions both inside and outside our own university. However, there are limits to this success, and they lie where everyone's good will and good cheer conflict with the limitations and indignities of contract employment. For, while an academic unit can entice a new instructor who enters from out of field to adopt the basics of a writing studies approach for the purposes of continued teaching, it is harder to woo someone to more permanently become an active participant in the field if there are few resources or opportunities for career advancement.

In fact, a tangible danger is that a unit like ASRW can perpetuate the unwanted top-down dynamic it otherwise works hard to counteract: against our collective effort to produce a productive, collegial environment with a low sense of hierarchy, employment conditions continue to reinforce less productive, 
more top-down hierarchical relations. For instance, under the leadership of the unit's first chair, Katharine Patterson, new faculty members were mentored in small working groups that were each led by an experienced instructor. Collaboratively, the members of each working group designed professional development workshops and then delivered these to the whole team of instructors. Some of these working groups also set up highly reciprocal classroom visits-not unlike the teaching circles described by Marshall (Marshall, 2008) and the good practices distilled by Denise Comer (Comer, 2011). However, even the most carefully intentioned reciprocity of classroom observation can, under circumstances of precarious employment, be experienced as a form of surveillance. Such sense of surveillance is particularly present when reciprocal classroom visits occur in uncertain relation to contractually stipulated forms of teaching assessment. It can be hard to distinguish an ongoing practice of collegial classroom visits from formal, evaluative classroom observation when it is the same instructor requesting both kinds of visits. If, as is the case in ASRW, only a very small number of instructors are in secure contracts that include the work of service and governance, then the requirement of summative teaching review that is written in the university's collective agreement can turn classroom visits into an instrument by which the few who are trained in the field need to continuously assess the many. An atmosphere of shared governance and reciprocal relations is difficult to maintain with such an imbalance (Darroch, 2017; Thieme, 2017).

Under conditions of precarious employment for the majority of teachers of writing, professional mentoring and requests for disciplinary exchange can feel like micro-managing, and emphasis on the technical language of the field may feel like being tested for compliance. As a unit that thrives on disciplinary exchange, ASRW is more successful than ever before in part through its emphasis on mentoring and metalanguage; however, it is still faced with a negative combination of writing studies' lack of disciplinary status and the precarity of its instructors. In addition to this combination of lack of disciplinary status and instructor precarity, the university's need to assess and monitor teaching excellence can seriously impede the overall goals of our pedagogy and our collegiality, much in the same way that the overarching requirement for graded assessment can impede our students' ability to learn and to collaborate with each other. In cases when a small number of tenure-track instructors become the purveyors of research-based practices to the point that they are in an exclusive position of mentoring, peerreviewing, and supervising the teaching practices of a particular set of other instructors who remain in contract positions, tenure-track instructors are also potentially deprived of some of the professional growth and disciplinary development that can benefit their work.

Robert Samuels argues that "the central dialectic between labor conditions and the field of writing studies" is that writing is seen "as a simple skill that can be taught by anyone in a single lower-division 
Volume 29, 2019

http://journals.sfu.ca/cjsdw

course," a view that justifies institutional reliance on contract labour, lower pay, and reductive writing curricula (Samuels, 2017, p. 19). Writing studies faculty and their allies at UBC have continuously demonstrated and asserted their field expertise in the eyes of the institution. Inside the institution, we have changed and are changing the perception of writing as a simple skill that anyone who writes can teach, the idea that teaching writing is a surface activity that requires little theoretical depth. More and more we are able to assert the demand that instructors who are hired to teach writing studies courses at our institutions need to have relevant disciplinary expertise and be active participants in professional networks for writing and applied language studies. In other words, we have enacted what Samuels calls, somewhat critically, a "logical argument" that relies on "enhancing the status of writing faculty by professionalizing the field and demonstrating student learning" (Samuels, 2017, p. 20). The move away from surface conceptions related to the teaching of writing towards in-depth knowledge of the field, as well as integration of its metalanguage in teaching are integral parts of this process of professionalization. Under conditions of ongoing precarity of instructors' employment conditions, such efforts at professionalization can only remain incomplete. What we need to do more of is asserting our need for better working conditions through collective action and through the work of our professional association (Mueller, Williams, Phelps, \& Clary-Lemon, 2017; Phelps, 2014).

\section{Acknowledgements}

This article was written on the traditional, unceded, and ancestral territory of the Musqueam people. My project owes its existence to Heidi Tiedemann Darroch, who envisioned both the panel where it was first presented and the special section of $C J S D W / R$ in which it now appears in full form. For their generous feedback, I extend my gratitude to my colleagues Laila Ferreira and Laurie McNeill, as well as to my mentor Katharine Patterson.

\section{References}

Adler-Kassner, L., \& Wardle, E. (2015). Naming what we know: Threshold concepts of writing studies. University Press of Colorado. 
Alexander, K. (2005). Liminal identities and institutional positioning: On becoming a "writing lady" in the academy. Inkshed: Newsletter of the Canadian Association for the Study of Writing and Reading, 22(3), 5-16.

Artemeva, N. (2008). Toward a unified social theory of genre learning. Journal of Business and Technical Communication, 22(2), 160-185. https://doi.org/10.1177/1050651907311925

Berry, R. (2005). Making the most of metalanguage. Language Awareness, 14(1), 3-20. https://doi.org/10.1080/09658410508668817

Comer, D. K. (2011). Bending the gaze: Transparency, reciprocity, and supervisory classroom visits. Pedagogy, 11(3), 517-537.

Darroch, H.T. (2017). Specialization, status, and stigma: Teaching-stream roles in researchintensive institutions. ESC: English Studies in Canada, 43(1), 4-7. https://doi.org/10.1353/esc.2017.0001

Downs, D., \& Wardle, E. (2007). Teaching about writing, righting misconceptions: (Re)envisioning "First-Year Composition" as "Introduction to Writing Studies." College Composition and Communication, 58(4), 552-584.

Duff, P. A., Ferreira, A. A., \& Zappa-Hollman, S.. (2015). Putting (functional) grammar to work in content-based English for academic purposes instruction. In MaryAnn Christison, Donna Christian, Patricia A. Duff, \& Nina Spada (Eds.), Teaching and learning English grammar: Research findings and future directions: A festschrift for Betty Azar (pp. 139-158). New York; London: Routledge.

Giltrow, J. (2016). Writing at the centre: A sketch of the Canadian history. Canadian Journal for Studies in Discourse and Writing/Rédactologie, 26, 11-24. 
Giltrow, J., Gooding, R., Sawatsky, M., \& Burgoyne, D.. (2014). Academic writing: an introduction (Third edition). Peterborough, Ontario: Broadview Press.

Halliday, M. A. K., \& Martin, J. R. (1994). Writing science: Literacy and discursive power. New York : Florence: Routledge.

Hyland, K. (2003). Genre-based pedagogies: A social response to process. Journal of Second Language Writing, 12(1), 17-29. https://doi.org/10.1016/S1060-3743(02)00124-8

Hyland, K. (2004). Disciplinary discourses: Social interactions in academic writing. Ann Arbor: University of Michigan Press.

Hyland, K. (2006). English for academic purposes: An advanced resource book. London ; New York: Routledge.

Landry, D. L. (2016). Writing studies in Canada: A people's history. University of British Columbia. https://doi.org/10.14288/1.0308778

Landry, D., \& Thieme, K. (under review). From literary to writing studies: Ghost stories in the academic machine. Canadian Journal for Studies in Discourse and Writing/Rédactologie.

Marshall, M. J. (2008). Teaching circles: Supporting shared work and professional development. Pedagogy, 8(3), 413-431.

Martin, R. (2003). Foreword. In M. Bousquet, T. Scott, \& L. Parascondola (Eds.), Tenured bosses and disposable teachers: Writing instruction in the managed university.. Carbondale: Southern Illinois University Press.

Mueller, D., Williams, A., Phelps, L. W., \& Clary-Lemon, J. (2017). Cross-border networks in writing studies. Edmonton, AB; Anderson, SC: Inkshed and Parlor Press. 
Nickoson, L., Sheridan, M. P., \& Kirsch, G. E. (2012). Writing studies research in practice: Methods and methodologies. Southern Illinois University Press. Retrieved from https://muse.jhu.edu/book/17157

Phelps, L. W. (2014). The historical formation of academic identities: Rhetoric and composition, discourse and writing. Canadian Journal for Studies in Discourse and Writing/Rédactologie, 25(1). Retrieved from http://journals.sfu.ca/cjsdw/index.php/cjsdw/article/view/37/22

Samuels, R. (2017). The politics of writing studies: Reinventing our universities from below. Logan, UT: Utah State University Press. https://doi.org/10.2307/j.ctt1v2xts5

Schleppegrell, M. J. (2013). The role of metalanguage in supporting academic language development. Language Learning, 63(s1), 153-170. https://doi.org/10.1111/j.14679922.2012.00742.x

Smith, T. S. (2006). Recent trends in undergraduate writing courses and programs in Canadian universities. In R. Graves \& H. Graves (Eds.), Writing centres, writing seminars, writing culture: Writing instruction in Anglo-Canadian universities (pp. 319-370). Winnipeg: Inkshed Press.

Swales, J. M. (2004). Research genres: Explorations and applications. Cambridge, UK ; New York: Cambridge University Press.

Thieme, K. (2016, October 10). What do you teach when you teach writing? Retrieved April 20, 2017, from https://medium.com/@KatjaT/what-do-you-teach-when-you-teach-writinge559e7c6643d

Thieme, K. (2017, December 3). On swimming in the tenure-track teaching stream [medium.com]. Retrieved June 12, 2018, from https://medium.com/@KatjaT/on-swimming-in-the-tenuretrack-teaching-stream-8c87cfd2dfe6 
Volume 29, 2019

http://journals.sfu.ca/cjsdw

Wardle, E. (2013). Intractable writing program problems, kairos, and writing about writing: A profile of the University of Central Florida's First-Year Composition program. Composition Forum, 27. Retrieved from http://compositionforum.com/issue/27/ucf.php 